\title{
Prepartum Maternal Plasma Glucose Concentrations and Placental Glucose Transporter mRNA Expression in Cows Carrying Somatic Cell Clone Fetuses
}

\author{
Hiroki HIRAYAMA ${ }^{1)}$, Ken SAWAI'), Muneyuki HIRAYAMA ${ }^{3)}$, Tomokazu HIRAI ${ }^{4)}$,

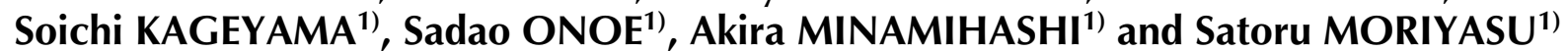 \\ 1)Animal Research Center, Hokkaido Research Organization, Hokkaido 081-0038, ${ }^{2)}$ Department of Animal Science, \\ Faculty of Agriculture, Iwate University, Iwate 020-8550, 3) National Livestock Breeding Center, Fukushima $961-8511$ and \\ ${ }^{4)}$ National Livestock Breeding Center Tokachi Station, Hokkaido 080-0572, Japan
}

\begin{abstract}
In this study, the plasma glucose concentrations of cows carrying a somatic cell clone fetus during late pregnancy and placental glucose transporter (GLUT) mRNA levels at parturition were examined. Parturition was induced using dexamethasone, prostaglandin $\mathrm{F}_{2 \alpha}$ and estriol in cows bearing a clone (Clone) or a fetus fertilized in vivo as a control (DEX). Plasma glucose concentrations were measured in the cows (days 257 and 271 of pregnancy and at parturition) and newborn calves. Cotyledon and caruncle tissues removed just after parturition were used for mRNA extraction. Expression of mRNA was also analyzed in control cows that were induced to undergo parturition without dexamethasone (PG) or that spontaneously delivered (SP). The glucose concentrations of the Clone group were significantly low at all points examined, but those of the calves were normal. The increase in the maternal glucose concentration from day 257 to parturition was significantly lower in the Clone group. Glucose concentrations were negatively correlated with birth weight for clones (day 257; $r=-0.584$, day $271 ; \mathrm{r}=-0.286$, parturition; $\mathrm{r}=-0.549$ ). There was no difference in mRNA levels in the cotyledons among the animals examined. In the caruncles, the Clone and PG groups showed significantly higher GLUT1 and GLUT3 mRNA levels than the SP group, and the GLUT3 mRNA level was significantly higher in the Clone group than in the DEX group. The glucocorticoid receptor $\alpha$ mRNA level was significantly lower in the SP group than in the DEX group. Although spontaneous parturition and administration of dexamethasone suppressed the placental GLUT mRNA levels, the action was not observed in clone pregnancy. These results raise the possibility of facilitation of glucose transportation through the placenta to meet increased nutritional requirements of overgrown clone fetuses.
\end{abstract}

Key words: Clone, Cortisol, Glucose, GLUT, Placenta

(J. Reprod. Dev. 57: 57-61, 2011)

C attle cloning by somatic cell nuclear transfer has been expected to improve the efficiency of animal breeding and to have advantages in the efficient production of genetically-engineered animals. However, low production efficiency remains a barrier to the practical application of the technology. A high incidence of gestational loss in early to mid-pregnancy is the most remarkable feature of the cloning of cattle [1], but problems in the peripartum period, such as delayed parturition, large offspring syndrome (LOS) and neonatal death, are also factors in decreasing the production efficiency [1-4]. LOS and poor sign of parturition in pregnant cows cause dystocia leading to losses of dams and newborn calves.

Cortisol, a glucocorticoid secreted from the fetal adrenal cortex, plays an important role in the initiation and progression of parturition $[5,6]$. The secretion of cortisol from the fetal adrenal cortex is facilitated particularly during the last week of gestation and reaches a peak just before parturition [5]. In the placenta, cortisol promotes the synthesis of estrogens that induce relaxation and dilation of the

Received: March 13, 2010

Accepted: August 18, 2010

Published online in J-STAGE: September 24, 2010

C 2011 by the Society for Reproduction and Development

Correspondence: H Hirayama (e-mail: hirayama-hiroki@hro.or.jp) birth canal [7]. Furthermore, cortisol downregulates fetal growth and stimulates the maturation of those organs essential for extrauterine survival, such as the lungs and thyroid [8]. Previously, we reported an insufficient increase of the prepartum estrogen concentration in pregnant cows carrying a clone fetus [9]. LOS and respiratory distress syndrome are also frequently observed in neonatal clone calves [2]. These findings imply that disruption of cortisol secretion in clone fetuses is a principal cause of the problems in the peripartum period. Chavatte-Palmer et al. [3] reported that the responsiveness of the adrenocortical tissue to adrenocorticotrophin in clone calves is normal, and we have also shown that clone calves had the ability to secrete cortisol at parturition [9]. However, the secretion of cortisol in prepartum clone fetuses is not fully understood.

Glucose is essential for fetal growth and is transported through the placenta from maternal blood to the fetus during pregnancy. Facilitated fetal cortisol secretion causes an increase in the concentration of glucose in maternal blood by its insulin antagonistic action [10]. Furthermore, glucocorticoid is involved in regulating the expression of placental glucose transporter (GLUT) 1 and 3 [11], influencing the amount of glucose transported to the fetus and fetal growth. Therefore, the glucose concentration in maternal blood and placental GLUT expression could be useful as parame- 
ters to investigate whether clone fetuses secrete cortisol normally during late pregnancy.

The concentration of glucose in the maternal circulation is affected by nutritional repletion of pregnant animals [12], and a reduced concentration correlates with insufficient fetoplacental development, leading to neonatal weakness [13]. The nutritional requirements of fetuses also affect the maternal glucose level, and twin-bearing cows show reduced glucose concentrations that might be induced by the increase of the placentome number and/or consumption of nutrition by the fetuses $[14,15]$. Therefore, it is expected that clone pregnancies with fetal overgrowth and neonatal death involve changes in the maternal glucose level that accompany fetal abnormality.

Here, correlations between the glucose concentration in maternal blood and abnormality of clone calves were examined through analyses of the glucose concentration in maternal blood, the birth weights of clone calves and GLUT mRNA expression levels in the term placenta. In addition, we examined the influence of dexamethasone, a synthetic glucocorticoid used to induce parturition as an alternative to fetal cortisol, on GLUT mRNA expression in the term placenta.

\section{Materials and Methods}

\section{Animals and treatment}

Clones were produced by nuclear transfer using fibroblasts from the skin of male Japanese black calves for donor nuclei. The procedures for production of clones were described previously [16]. Control calves (Japanese black) were produced by transferring embryos fertilized in vivo into recipient cows. The calves were born at the Hokkaido Animal Research Center (HARC) and the National Livestock Breeding Center Tokachi Station (NLBC). The production of cloned cattle was approved by the Animal Experiment Committee. In both facilities, the recipient cows were fed grass hay and grass silage, and the herds were comprised considering body constitution and social hierarchy.

The induction of parturition in cows carrying a clone (Clone) was achieved with $20 \mathrm{mg}$ i.m. dexamethasone (Denka Pharmaceutical, Kawasaki, Japan), followed by prostaglandin $\mathrm{F}_{2 \alpha}\left(\mathrm{PGF}_{2 \alpha}\right.$; 0.75-1mg i.m. cloprostenol [Resipron-C, Aska Pharmaceutical, Tokyo, Japan] or 25 mg i.m. tromethamine dinoprost [Pronalgon-F injection, Pharmacia, Tokyo, Japan]) and $20 \mathrm{mg}$ i.m. estriol (Holin, Teikoku Zoki, Tokyo, Japan) 24 h later. Control cows were treated in the following three ways: administration of dexamethasone followed by $\mathrm{PGF}_{2 \alpha}$ and estriol $24 \mathrm{~h}$ later (DEX), $\mathrm{PGF}_{2 \alpha}$ and estriol without dexamethasone (PG) and spontaneous parturition without induction of parturition (SP). Calves were delivered 1 or 2 days after the administration of $\mathrm{PGF}_{2 \alpha}$ and estriol. Some clones were delivered by cesarean section after the induction of parturition. Beef breeds were used as recipient cows for collection of blood (HARC, Angus and crossbreed; NLBC, Japanese black, Japanese brown and crossbreed) and placentomes (HARC; Japanese black, Angus, Hereford and crossbreed).

\section{Sample collection}

Venous blood samples of the Clone group were taken at days
257 and 271 of gestation and just before parturition. Venous blood samples of the DEX group were taken on the same days of gestation as for the control. Venous blood samples of the calves were taken just after parturition. Plasma was harvested by centrifugation and stored at $-20 \mathrm{C}$ until the analyses.

Placentomes were collected manually, immediately after vaginal delivery and cesarean section, through either the birth canal or the incision made in the uterus. They were separated manually into two portions, the cotyledon (COT) and the caruncle (CAR), and stored at $-80 \mathrm{C}$ prior to the extraction of RNA.

The average length of gestation in the cows and calves used for blood collection was 284 days $(n=22)$ for the Clone group and 283 days $(n=6)$ for the DEX group. The average periods of gestation in the cows used to collect samples of placental tissue were 286 days $(n=14), 287$ days $(n=5), 286$ days $(n=4)$ and 293 days $(n=4)$ for the Clone, DEX, PG and SP groups, respectively.

\section{Glucose concentrations}

Plasma glucose concentrations were measured with Synchron system Glucose Reagent (reference number 442640, Beckman Coulter, Tokyo, Japan) and a Synchron CX5 Delta Clinical System (Beckman Coulter).

\section{Reverse transcription and real-time PCR}

Total RNA was individually isolated from COT and CAR using ISOGEN (Nippon Gene, Toyama, Japan) and reverse transcribed using a QuantiTect Reverse Transcription Kit (Qiagen, Valencia, CA, USA) according to the manufacturer's instructions.

Real-time PCR was performed (run in duplicate) using a QuantiTect SYBR Green PCR Kit (Qiagen) and a Chromo 4 Real-time PCR system (Bio-Rad Laboratories, Hercules, CA, USA) with the following primers: 5'-AGCGTCATCTTCATCCCAGC-3', forward, and 5'-CCACAATGCTCAGGTAGGAC-3', reverse, for GLUT1 and (annealing temperature: 58 C [17]); 5'-ATGGCAGTGGCTGGTTGTTC-3' and 5'-TCCTGAGCTGAAGAGAATGTCC-3', for GLUT3 (58 C [17]); 5'-CCATTTCTGTTCACGGTGTG-3' and 5'-CTGAACCGACAGGAATTGGT-3' for Glucocorticoid receptor $\alpha(G C-R \alpha$; 55 C [18]); and 5'-CCAGAAGACTGTGGATGGCC-3' and 5'-CTGACGCCTGCTTCACCACC-3' for GAPDH (60 C [19]). The thermal cycling conditions included activation of HotStarTaq DNA Polymerase at $95 \mathrm{C}$ for $15 \mathrm{~min}$, followed by 45 cycles of denaturation at $94 \mathrm{C}$ for 15 sec; annealing of primers at different temperatures for $30 \mathrm{sec}$; and elongation at $72 \mathrm{C}$ for $30 \mathrm{sec}$. To quantify the mRNA abundance, standard curves for each gene were generated by serial dilution of a known quantity of purified RT-PCR products. The relative difference in the initial amount of each mRNA species was determined by comparing the $\mathrm{Ct}$ values. We confirmed the melting curve for detecting the SYBR Green-based objective amplicon because SYBR Green also detects double-stranded DNA, including primer dimers, contaminating DNA and PCR products from misannealed primers. The expression of each gene relative to that of GAPDH mRNA was calculated for adjustment of the amount of RNA used in the RT-PCR. 


\section{Statistical analysis}

All results are presented as means \pm S.E.M. Statistical analyses were performed using the Student's $t$-test and one-way ANOVA followed by Scheffé's test. The relationships between maternal glucose concentrations and birth weights of calves were evaluated using Pearson's correlation coefficient.

\section{Results}

\section{Glucose concentration}

As shown in Table 1, the maternal plasma glucose concentrations were unchanged between days 257 and 271 of gestation, but increased significantly at term in both the Clone and Control groups. The plasma glucose concentrations were significantly lower in the Clone group than in the Control group during the period examined. The increase in the plasma glucose concentrations at term was lower in the Clone group than in the Control group and there was a significant difference in the ratio of Term to day 257 of gestation. There was no difference in the plasma glucose concentrations of calves at birth between the Clone and Control groups.

\section{GLUT1, GLUT3 and GC-R $\alpha m R N A$ expression in the placentome}

The GLUT1, GLUT3 and GC-R $\alpha$ mRNA levels in the COT did not differ among the Clone and Control (DEX, PG and SP) groups (Fig. 1A, C and E).

GLUT1 mRNA expression in the CAR was significantly higher

Table 1. Maternal plasma glucose concentrations in late pregnancy and plasma glucose concentrations of newborn claves

\begin{tabular}{lcc}
\hline & \multicolumn{2}{c}{ Animals } \\
\cline { 2 - 3 } & Clone & Control \\
\hline Number of dams/calves & 22 & 6 \\
Maternal glucose & $56.2 \pm 1.1$ & $62.2 \pm 1.0^{* *}$ \\
Day 257 (mg/dl) & $52.9 \pm 1.8$ & $62.2 \pm 1.6 * *$ \\
Day 271 (mg/dl) & $81.8 \pm 3.8^{\dagger}$ & $106.2 \pm 11.8^{* *},{ }^{\dagger}$ \\
Term (mg/dl) & $1.455 \pm 0.058$ & $1.705 \pm 0.185 *$ \\
Term / Day 257 & $1.562 \pm 0.068$ & $1.712 \pm 0.198$ \\
Term / Day 271 & $45.4 \pm 3.5$ & $47.5 \pm 4.2$ \\
Calf glucose (mg/dl) & & \\
\hline
\end{tabular}

$* \mathrm{P}<0.05, * * \mathrm{P}<0.01$ : significant differences between the Clone and Control groups. ${ }^{\dagger} \mathrm{P}<0.01$ : significant difference compared with the maternal plasma glucose concentrations at days 257 in each animal.
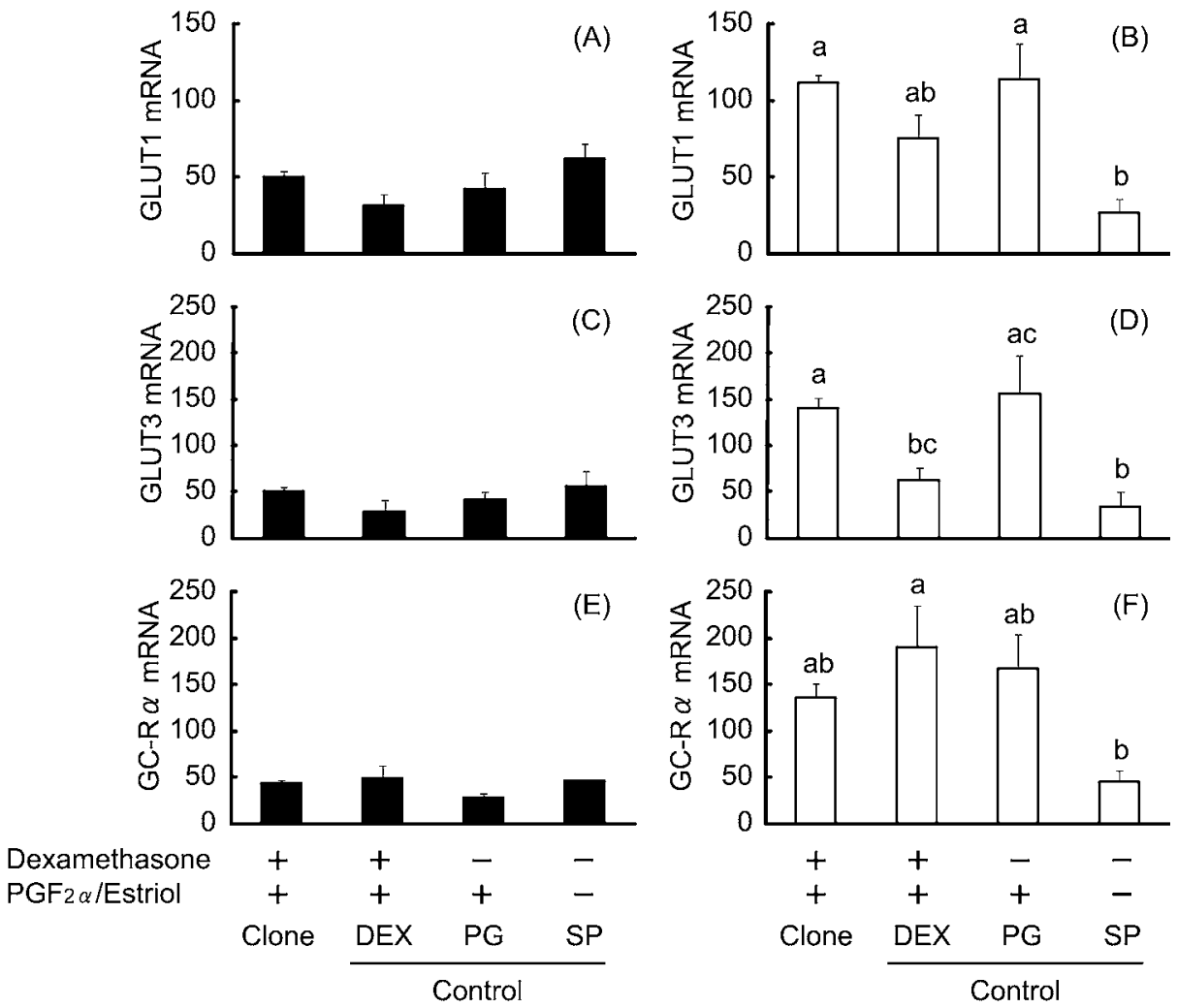

Fig. 1. GLUT1, GLUT3 and GC-R $\alpha$ mRNA levels in term placental tissues. The abundance of mRNA in cotyledonary (A, $\mathrm{C}$ and $\mathrm{E}$ ) and caruncle (B, D and F) tissues was analyzed by real-time RT-PCR. Cows carrying a somatic cell clone (Clone) were induced to undergo parturition with an administration of dexamethasone, PGF $_{2 \alpha}$ and estriol. Cows carrying an in vivo-fertilized fetus were induced to undergo parturition in the same manner as the Clone group (DEX) or with $\mathrm{PGF}_{2 \alpha}$ and estriol (PG), or the calves were delivered spontaneously (SP). 
in the Clone and PG groups than in the SP group (Fig. 1B). GLUT1 mRNA expression in the CAR tended to be lower in the DEX group than in the Clone and PG groups. GLUT3 mRNA expression in the CAR was significantly higher in the Clone group than in the DEX and SP groups (Fig. 1D). GLUT3 mRNA expression in the CAR was also significantly higher in the PG group than in the SP group. Although $G C-R \alpha$ mRNA expression in the CAR was significantly higher in the DEX group than in the SP group, there was no difference among the Clone, DEX and PG groups (Fig. 1F).

\section{Correlation between maternal glucose concentrations and birth weights}

The birth weight of the Clone group (48 $\pm 3 \mathrm{~kg}$ ) was significantly higher $(\mathrm{P}<0.01)$ than that of the DEX group $(27 \pm 1 \mathrm{~kg})$.

In the Clone group, the maternal plasma glucose concentrations at day 257 of gestation $(r=-0.584, \mathrm{P}<0.01)$ and term $(\mathrm{r}=-0.549$, $\mathrm{P}<0.01$ ) were correlated significantly with birth weight, and those at day 271 of gestation showed poor correlation $(r=-0.286, P=$ 0.198; Fig. 2).

In contrast, the maternal plasma glucose concentrations of the Control group (DEX) at days $257(\mathrm{r}=-0.084, \mathrm{P}=0.875)$ and $271(\mathrm{r}$ $=0.175, \mathrm{P}=0.740)$ of gestation and term $(\mathrm{r}=-0.479, \mathrm{P}=0.336)$ did not show significant correlation with birth weights.

\section{Discussion}

In this study, low maternal plasma glucose concentrations in clone pregnancies were associated with the incidence of LOS. This relationship was observed from 4 weeks before to just before parturition. A previous report revealed that overgrown clones were observed by day 100 of gestation when the facilitation of fetal cortisol secretion had not begun [20]. Additionally, clone calves showed normal plasma glucose concentrations at birth. Therefore, the decrease of the glucose concentration in the maternal circulation during late pregnancy seems to be due to excess glucose requirements of overgrown fetuses as in a twin pregnancy with normal fetuses rather than insufficiency of the insulin antagonistic action by fetal cortisol. Although it should be noted that the concentration of glucose in maternal blood is affected by the feeding conditions of herds, the current data raise the possibility that maternal glucose levels allow a rough estimate of the occurrence of LOS at least after the 4th week pre-parturition. Because dystocia caused by a lack of readiness for birth in pregnant cows and LOS may result in mortality of perinatal clones, information on birth weight would be useful to decide on a cesarean delivery.

The difference in GLUT mRNA abundance among the controls, which were induced to undergo parturition with/without dexamethasone or delivered spontaneously, indicated consecutive downregulation of placental GLUT mRNA expression as parturition proceeded. Thus, the mRNA levels of GLUT1 and GLUT3 in caruncles decreased on administration of dexamethasone compared with the induction of parturition using only prostaglandin $F_{2 \alpha}$ and estriol, and the lowest levels were observed after spontaneous delivery. Therefore, it was supposed that dexamethasone caused the decrease in placental GLUT mRNA expression and that endogenous cortisol suppressed it more strongly. This assumption is
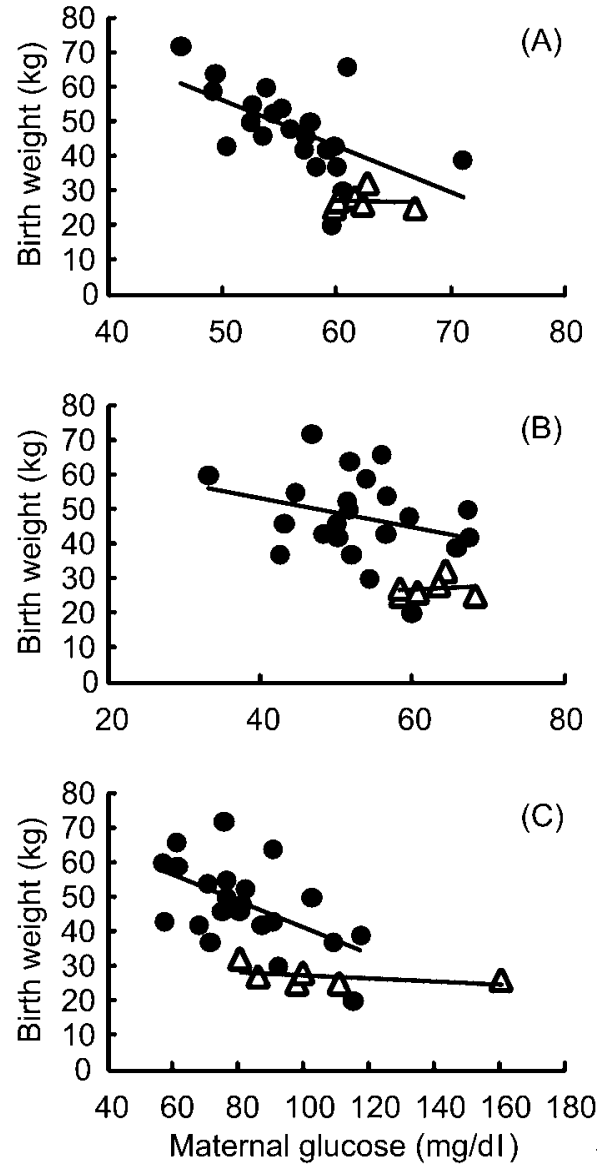

Fig. 2. Correlation between the maternal plasma glucose concentration in the prepartum period and birth weight of clones derived from somatic cell nuclear transfer. Plasma glucose concentrations in cows carrying a somatic cell clone $(\bullet)$ or a control fetus $(\triangle)$ were measured at days 257 (A) and 271 (B) of gestation and at term (C).

consistent with a previous study showing that glucocorticoid downregulates GLUT1 and GLUT3 mRNA and protein expression in human trophoblast cells and the rat placenta [11].

Placental GLUT mRNA expression in clone pregnancy did not decrease at parturition, despite the administration of dexamethasone. The ongoing expression implied an increase of glucose transportation to the clone fetuses. Clone and control pregnancies in which parturition was induced with or without dexamethasone showed similar placental GC-R $\alpha$ mRNA abundance, except for a decrease in $G C$ - $R \alpha$ mRNA abundance in the controls that delivered spontaneously. Therefore, the differences in placental GLUT mRNA levels seemed to be caused by the glucocorticoid levels in the placentome rather than disruption of signal transduction through the receptor.

The distribution of GLUT1 and GLUT3 in placentomes was studied in detail by Wooding et al. [12] using immunohistochemistry. GLUT1 was detected in the basolateral plasmalemmas of both the trophoblast lining the fetal villi and the caruncle epithelium. 
GLUT3 was detected in interdigitated areas of the trophoblast and the caruncle epithelium. We extracted mRNA from cotyledons and caruncles, respectively, and quantified GLUT mRNA abundances. Cotyledons showed less mRNA than caruncles, and the levels in cotyledons were constant among animals, mainly because the samples contained a fetal membrane overlying the placentome. In contrast, the abundance of GLUT mRNA was detected in caruncle samples including the placental labyrinth, which was occupied by the fetal villi and the caruncle epithelium.

The concentration of glucose in maternal blood remains stable during late pregnancy and then rises sharply before parturition [13]. This prepartum rise is caused by the insulin antagonistic activity of glucocorticoid [10]. Clone pregnancy also showed an increase in the plasma glucose concentration just before parturition; however, the increase was modest. It is possible that an insufficiency of fetal cortisol secretion at parturition caused the outcome, but the concentration of cortisol and the function of the hypothalamic-pituitaryadrenal axis in clone fetuses need to be confirmed in future studies.

In summary, the maternal plasma glucose concentration correlated inversely with birth weights of clone calves, and suppression of placental GLUT mRNA levels by administration of dexamethasone was not observed in clone pregnancy. These results raise the possibility of facilitation of glucose transportation through the placenta to meet the nutritional requirements of overgrown clone fetuses.

\section{Acknowledgments}

This study was supported by a Grant-in-Aid for Young Scientists (B), No. 21780255, from the Ministry of Education, Culture, Sports, Science and Technology of Japan.

\section{References}

1. Heyman Y, Chavatte-Palmer P, LeBourhis D, Camous S, Vignon X, Renard JP. Frequency and occurrence of late-gestation losses from cattle cloned embryos. Biol Reprod 2002; 66: 6-13.

2. Hill JR, Roussel AJ, Cibelli JB, Edwards JF, Hooper NL, Miller MW, Thompson JA, Looney CR, Westhusin ME, Robl JM, Stice SL. Clinical and pathologic features of cloned transgenic calves and fetuses (13 case studies). Theriogenology 1999; 51: 14511465.

3. Chavatte-Palmer P, Heyman $Y$, Richard C, Monget P, LeBourhis D, Kann G, Chilliard Y, Vignon X, Renard JP. Clinical, hormonal, and hematologic characteristics of bovine calves derived from nuclei from somatic cells. Biol Reprod 2002; 66: 1596-1603.

4. Pace MM, Augenstein ML, Betthauser JM, Childs LA, Eilertsen KJ, Enos JM, Fors- berg EJ, Golueke PJ, Graber DF, Kemper JC, Koppang RW, Lange G, Lesmeister TL, Mallon KS, Mell GD, Misica PM, Pfister-Genskow M, Strelchenko NS, Voelker GR, Watt SR, Bishop MD. Ontogeny of cloned cattle to lactation. Biol Reprod 2002; 67: 334-339.

5. Comline RS, Hall LW, Lavelle RB, Nathanielsz PW, Silver M. Parturition in the cow: endocrine changes in animals with chronically implanted catheters in the foetal and maternal circulations. J Endocrinol 1974; 63: 451-472.

6. Wood CE. Control of parturition in ruminants. J Reprod Fertil Suppl 1999; 54: 115-126.

7. Breeveld-Dwarkasing VN, Struijk PC, Lotgering FK, Eijskoot F, Kindahl H, van der Weijden GC, Taverne MA. Cervical dilatation related to uterine electromyographic activity and endocrinological changes during prostaglandin $\mathrm{F}_{2 \alpha}$-induced parturition in cows. Biol Reprod 2003; 68: 536-542.

8. Liggins GC. The role of cortisol in preparing the fetus for birth. Reprod Fertil Dev 1994; 6: 141-150.

9. Hirayama H, Sawai K, Moriyasu S, Hirayama M, Goto Y, Kaneko E, Miyamoto A, Ushizawa K, Takahashi T, Minamihashi A. Excess estrogen sulfoconjugation as the possible cause for a poor sign of parturition in pregnant cows carrying somatic cell clone fetuses. Reproduction 2008; 136: 639-647.

10. Plager JE, Matsui N. An in vitro demonstration of the anti-insulin action of cortisol on glucose metabolism. Endocrinology 1966; 78: 1154-1158.

11. Hahn T, Barth S, Graf R, Engelmann M, Beslagic D, Reul JM, Holsboer F, Dohr G, Desoye G. Placental glucose transporter expression is regulated by glucocorticoids. J Clin Endocrinol Metab 1999; 84: 1445-1452.

12. Wooding FB, Fowden AL, Bell AW, Ehrhardt RA, Limesand SW, Hay WW. Localisation of glucose transport in the ruminant placenta: implications for sequential use of transporter isoforms. Placenta 2005; 26: 626-640.

13. Zhan WC, Nakao T, Kida K, Moriyoshi M, Nakada K. Effect of nutrition during pregnancy on calf birth weights and viability and fetal membrane expulsion in dairy cattle. J Reprod Dev 2002; 48: 415-422.

14. Penny CD, Lowman BG, Scott NA, Scott PR, Voelkel S, Davies DA. Managemen aspects of induced twinning in beef suckler cows using in vitro fertilised embryos. Vet Rec 1995; 136: 506-510.

15. Dwyer CM, Calvert SK, Farish M, Donbavand J, Pickup HE. Breed, litter and parity effects on placental weight and placentome number, and consequences for the neonatal behaviour of the lamb. Theriogenology 2005; 63: 1092-1110.

16. Sawai K, Kageyama S, Moriyasu S, Hirayama H, Minamihashi A, Onoe S. Analysis of mRNA transcripts for insulin-like growth factor receptors and binding proteins in bovine embryos derived from somatic cell nuclear transfer. Cloning Stem Cells 2005; 7 : 189-198.

17. Augustin R, Pocar P, Navarrete-Santos A, Wrenzycki C, Gandolfi F, Niemann $\mathbf{H}_{\text {, }}$ Fischer B. Glucose transporter expression is developmentally regulated in in vitro derived bovine preimplantation embryos. Mol Reprod Dev 2001; 60: 370-376.

18. Lee HY, Acosta TJ, Tanikawa M, Sakumoto R, Komiyama J, Tasaki Y, Piskula M, Skarzynski DJ, Tetsuka M, Okuda K. The role of glucocorticoid in the regulation of prostaglandin biosynthesis in non-pregnant bovine endometrium. J Endocrinol 2007; 193: 127-135.

19. Sawai K, Kageyama S, Moriyasu S, Hirayama H, Minamihashi A, Onoe S. Changes in the mRNA transcripts of insulin-like growth factor ligand, receptors and binding proteins in bovine blastocysts and elongated embryos derived from somatic cell nuclear transfer. J Reprod Dev 2007; 53: 77-86.

20. Lee RS, Peterson AJ, Donnison MJ, Ravelich S, Ledgard AM, Li N, Oliver JE, Miller AL, Tucker FC, Breier B, Wells DN. Cloned cattle fetuses with the same nuclear genetics are more variable than contemporary half-siblings resulting from artificial insemination and exhibit fetal and placental growth deregulation even in the first trimester. Biol Reprod 2004; 70: 1-11. 